\title{
TEMPORAL DEPRESSION AND THE DISAPPEARANCE OF SHIPS
}

\section{Robert Clarke}

\section{ABSTRACT}

The following dialogue, between two fictional voices, concerns the phenomenological aspects of two closely related and marginal sub-genres: photographs of ships, and photographs taken aboard them by their crews. Whereas the first category is defined by its presentation of the external profile of a vessel in a single view, crew's photographs record their own lived experiences through manifold pictures of the 'internal' ship. In light of this, the discussion describes and questions the nature of appearance and temporality arising in both kinds of images, for one of the interlocutors.

Keywords: appearance, temporality, imaginary, depression

\section{PHOTOGRAPHS OF SHIPS}

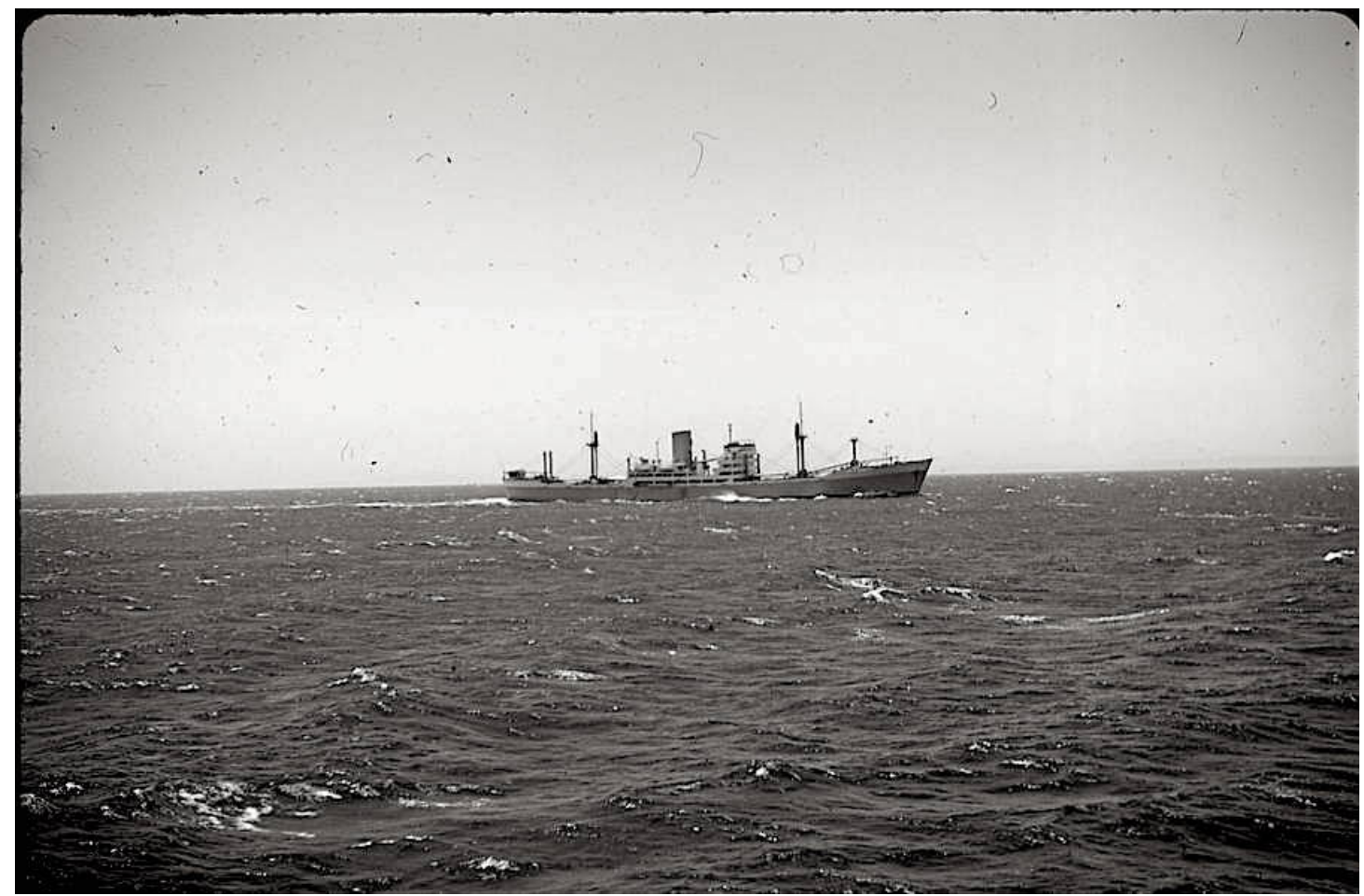

When I examine pictures like this, I'm struck by the lack of factual information attached to them. This sort of photograph tells us very little. All we have is a ship crossing left to right, or right to left, a surge of sea, some sky, and typically, that's it. They're intriguing, impecunious impressions, notable for a peculiar absence they have about them. Reality is experienced only in the present; it is what's abundantly present. Everything not physically present is in some degree imagined. The past can never be made present to us as it was lived in the presence of its immediacy. Nevertheless, it bequeaths us displaced traces in the form of culture, civilization, technology, documents, and so forth, which with inescapable curiosity we use to imagine, memorialise and come to terms with our place in time.

But aren't we connected by objects, all of which are "time pieces"? 
Indeed. You could go to an archive and, let's say, hold Sigmund Freud's pocket watch in the palm of your hand. But the watch you'll see won't be the time Freud glanced at. When it comes to time, we can't live what he saw. We can imagine what the present might have looked like for him but we can never experience it as he did - as something lived, drifting through him, or he through it, instant-by-instant.

And in this photo, is the ship any different?

I enter the image only in the present. It doesn't show me a real, three-dimensional vessel, only a flattened paper impression of one. I happen to know this ship existed, that it's not a fake photo. If I chose, I could find more pictures of the ship and other documents to prove it once existed. I might even be able to track down former crew members. Whatever I make of the photo, somewhere else there will be further evidence to corroborate the freighter's existence.

But for now, without recourse to that, we have here a single picture, an isolated photograph. So what does it suggest?

It suggests time.

How?

Whenever I look at photos, immediately I'm aware of the passage of time - the lapse between the present moment of my gaze and the moment the photographer took the picture; a lapse which, in this example, marks a difference between an actual ship and an imaginary one. An imaginary ship is signified by any form of its representation. Any attempt to describe a ship - in images, words, and so on, leaves us with an imagined ship and not a ship as the thing itself, as a constructed, three-dimensional vessel before us in the here and now.

Isn’t reaching through the description for the unrepresented ship, impossible?

It is. For as soon as we reach for it, we're imagining it again, and that is itself a representation. Moreover, in such cases our imagined representation, or picturing, seems to bear little resemblance to the actual thing. Indeed, perhaps it's always the case that anything imagined anything at all - never resembles the object of its origin. As we know, there's a profound distinction between a physical object, such as a vessel, and the mental content we have of it. The imagined is not a facsimile of the real. However, once I approach a mediated form of appearance such as photography, I find the ship is even further removed and elusive, as if it I'm attempting to chase after a mirage.

And yet although the photograph we have before us appears to represent a ship in a matter-offact, rather banal, documented way, you seem to be suggesting something else is at work.

I see a contradiction in the whole convention underlying these kinds of pictures. On the one hand, such a photo conveys the credible existence of an actual ship, showing us with limited precision what the ship looked like. The intention behind the photo is informational which, in the circumstances, is prosaic. However, on the other hand, despite that intention, so much is obscured that one is struck by the scale of what's missing.

Do you mean that most of the ship's appearance is missing because a photo only ever shows us a single profile, determined by the position of the camera?

Certainly, it is the case that our perspective limits how much can be disclosed in a single image, and as a consequence, we see only what is immediately in view as a spatial relationship between the vessel and the camera. However, it occurs to me that what's missing is not so much the 
obscured appearance - for instance, the opposite side of the hull that's hidden from us - but time itself. This is the scale of the absence. The effect of the photo is one of enormous compression. It is as though the temporal relationship with appearance, that you'd barely experience in the presence of an actual ship, is in its mediated form as a photo, darkened by the mass of something heavy.

'Heavy' in the sense of a lowering of mood, of something depressing?

I do. The lack of perspective given in a single, fixed appearance like this one, is compounded by the fact that we can never get behind the photo to see around the back of the ship, or sail in it. It's an absurd wish. Yet, despite that, because it's ungratified the mood lowers into what I call a "temporal depression".

The unconscious wish to inhabit the reality suggested by an image goes unfulfilled. And this leads to a depressed state related to a sense of time?

It does. It may not qualify as a clinically lowered mood, for it's fleeting, but certainly it's shadow passes through you. I believe it arises out of the failure of images to live up to the reality they purport to show. The differential between what is actually present and what is an illusion can make the promise of images seem hollow. Paradoxically, we rely so much on them for productive, playful, imaginary purposes - illusions stimulate us, yet nevertheless, when you examine them, they're empty. When I realised this, I couldn't look at art without sensing the depression that swam beneath it. It's a relative emotion of course, but I experience it as a negative influence that has something to do with feeling that time has infinitely huge mass. In this simple photo, the weight of it crushes the ship out of existence.

And leaves us with what?

It leaves us with nothing but the present. Yet we cannot live long in the present - back and forth, we chase after it, or else run away in a pathological recourse to the past that we know only from the imaginary potency of memories.

Why does that bother you?

Because on gazing at these pictures, I'm depressed by the colossal of weight of time in them, by the radical but indefinite dispossession of ground. Nowadays, I do not see what is there, only what's missing; it's a form of existential displacement. It's as though on resort to something familiar in an image, where we might look to get our bearings, we discover that upon each return, something else has collapsed we were sure was intact last time; and then you sense the groundlessness.

Do you mean the ship in the picture no longer exists?

Certainly that has a lot to do with this kind of disappearance. There's also the absence of information surrounding the origin of the photograph - the moment in which it was snapped. I find myself wanting to know the precise date, even the time of day, when the picture taken. I know it's unnecessary; knowing the date wouldn't change anything. What purpose could possibly be served by knowing, for instance, that this picture here, of an unidentified cargo ship, was taken at $2.31 \mathrm{pm}$ on Thursday 2 May 1963, as it steamed south across the Bay of Biscay. It's ridiculous. Nevertheless, whenever I thumb through photographs, the desire to pin down the exact moment of their capture, comes to the surface.

Perhaps there's something else associated with that wish. For example, we could say that knowing the date serves no obvious practical purpose; as you mentioned: what would you do with that knowledge if you possessed it? However, another way of considering this, is not so much to think about recovery of the time or date, as such. Rather, it might be more valuable to 
think about what motivates the wish to know it. Let me put it back to you: why is it important for you to know the date?

I don't really know. However, I suspect the answer is an existential one. I want to know whether or not the ship in a photo intersects with my own life. In other words, I'm looking to discover whether I was alive when it was photographed. It's about the coincidence of two events - the origin of the photograph and my own life somewhere else. When I find a picture like this one, I have the thought: "Where was I when this was taken?"

What happens when it's obvious that the photo you're looking at was taken before you were born?

Then, the relationship between myself and the picture is entirely different. I see what's there with greater detachment, more distance. It's as though I'm free of any responsibility! That's not to say I can't be moved by a photograph that happens to pre-date me, because, of course, I can. But even so, I do not detect the ambivalence I feel when I'm looking at a photograph whose moment of capture, and the world it shows, coincides with the interval of my own life.

In a nutshell: the latter sort of photos have a special connection because of two events - when a picture was taken, and a life being lived - and when these coincide they influence how we see what's there?

Yes.

What happens when you aren't sure of a picture's date? For instance, an ambiguous one in which the ship existed before you were born, but which may have been still around afterwards?

There's a curiosity to find out, as if to settle the question. I should say that usually, I don't find out - I don't try to. My point is that the question exists, nonetheless.

What about a photograph whose date is known and happens to be a year or two before your birth? What is the relationship with them?

Whenever there's an overlap, pictures seem to become more interesting. If a ship has survived to connect with the period of my childhood, merged with it chronologically, then something is opened up that's not the case when it's clear there's no contiguity. For example, if I look at a photo of the Titanic, I know it represents something beyond any lived connection of mine. 1912 is too distant, the event too mythological to judge the reality of what it truly meant; it touches me, but not with the imaginary power it might have had, had it hit the iceberg in the 1960s.

Is this because what lives when you live has a reality about it that nothing else has?

Mainly it does. Everything that falls outside the span of a life seems remote, detached, shadowed; it's as though it's bracketed off into a separate part of consciousness.

Bracketed from what?

Bracketed from the emotional context of whatever occurs in the world within the duration of our own lives; outside that, it's 'historical'.

Whereas, everything which occurred in the world during, or in a handful of years leading up to our birth, is not? 
We are saturated by history; the 1960s of my childhood is history, already. Nevertheless, because I grew up then, it remains potent and accessible. And since it resides in me it's not objectified in the way I might relate to history. It's hard to accept wholly that what we live through, is history. I can't look at the sixties and be indifferent to them in the way I can with, say, the thirteenth-century.

There's a difference between lived experience and history, and for you, photographs of ships signify that difference?

The difference expresses how we measure time subjectively according to the reach of our own experience. It's as though I'm looking at life through these things, knowing that for the time being, I do not yet belong to history, but like the ship in the photograph, one day, I will, obviously. That's the source of the temporal depression intimated by these images; it's all there in the disappearance of ships.

\section{CREW PHOTOGRAPHS}

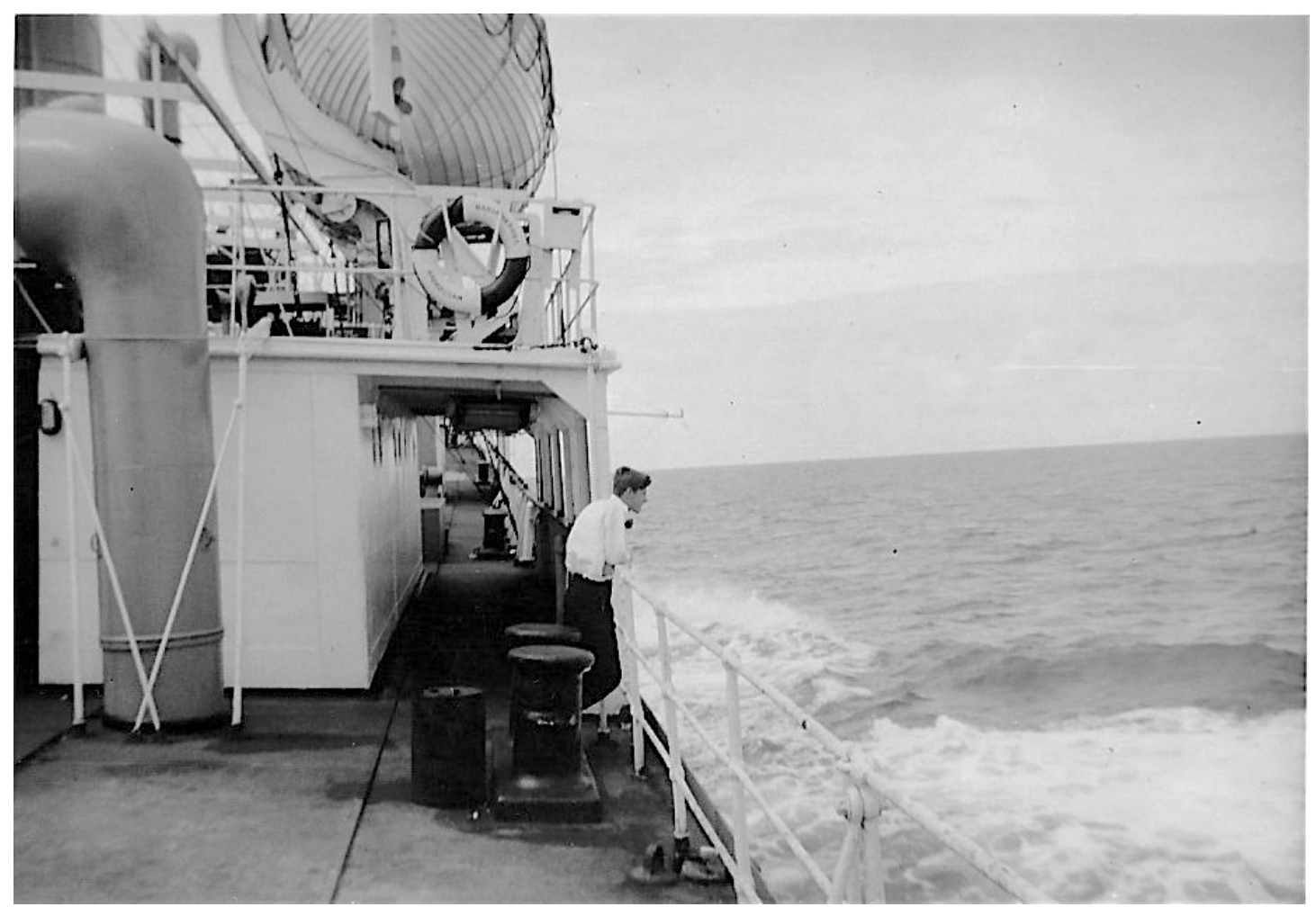

By 'crew photos' we mean those taken by sailors aboard a ship. So instead of the camera viewing a ship from a distance - as in the previously discussed photographs - the crew's cameras are inside the vessel, and as such they're part of its 'subjectivity', seeing both a world within while also observing the horizon all around. Thus, sailors' photos illuminate the difference between objective and subjective accounts of the single presence of a ship.

I see. So loosely, could we say that photographs in which the intention is to gather the overall appearance of a ship into a single view, and which therefore must be taken from some distance, have an objective ambition. They perform the role of a detached observer. Whereas, crew photos emanate an atmosphere of subjectivity. And, from these different purposes - the onlookers' and the crews' - we experience two separate accounts of one and the same vessel? 
Exactly: two intentions within an almost infinite series possibilities by which a ship might appear as an image. All that either of these intentions can show is the merest fraction of the whole vessel.

The "whole vessel" being what?

The 'whole' meaning the infinite accumulation of every conceivable view: inside and out, masthead to keel, from every position and angle. All of which might be said to represent the unimaginable totality of a ship, the inexhaustible reality of its appearance.

The "inexhaustible reality" is the transcendental vessel, is it not?

It's an entertaining idea that represents the logically impossible attempt to imagine a ship as a singular presence in which all it contained was perceived simultaneously from every possible position, where all the profiles and manifolds were merged into sublime one.

It is an inconceivable object - unlike the two sets of photographs under discussion.

Indeed, although the ship appears in both types of photo, the photographers' relationship with their subject comes from opposite ends of involvement: the internal and the external points of view.

Would you say that what's internal to the ship can only be experienced by being aboard it?

Where taking photographs are concerned, that's necessarily the case. I used to be a sailor. I observed ships long before I went aboard one. However, the moment of going aboard, climbing the ladder, and from there, looking down and seeing the narrow band of water that separated the hull from the dock, seemed to me to be a significant, vertiginous moment. That narrow channel of oily water, the climb up the juddering gangway, and so on, defined a threshold marking the outside world from one which felt altogether more internal. As you stepped over the combing into the vessel, your perspective altered - suddenly, you were part of the ship, and the ship was part of you. Something perceptual was being internalised that shifted your relationship with horizons. Another world, a small finite one closed in, and beyond it, the timeless ocean. I felt it. This is why, for me, photographs taken aboard ships are often mesmerising.

Are there differences of content within this category of photos?

Naturally, there are qualitative differences: some occur at the level of the literal content, some because of formal considerations, others because of the accidental aesthetics over which the photographer had no control. All these characteristics can contribute to the poetic structure and impact of a photo.

Are sailors' photos mainly pictures taken of each other?

Generally, they are; although, that's not to say seafarers don't take pictures ashore. However, their results are little different from any tourist snaps. What is distinctive are the photos taken aboard ship. After all, out at sea they're in the presence of the vast emptiness of the ocean whose vacant states are disturbed only by the weather; there's only so much one can show of this in a photograph. Consequently, the camera turns inward and falls upon the ship and one's shipmates, and the relationship between them.

Does the ship itself dominate these images - sailors taking pictures of their ship, from on board? 
It's always a presence, a background. However, the overwhelming focus is upon the crew: the kinship of an eccentric, itinerant life with its routines of navigation and maintenance, boredom, boiler-suits, and booze. Almost all these pictures are informal and relaxed, figures standing shyly or sat around, idling for the camera, unruffled, insouciant. When I gaze at them I feel liberated from the tedious self-consciousness that personal photography has become today.

You're referring to the phenomenon of the so-called 'selfie'?

I lament the loss of artlessness - and reserve. Digital technology has turned us into the most shameless narcissists who've ever lived. We are inundated by images of self-referential vacuity. In themselves such things are harmless trifles, but collectively, culturally, they seem to be symptomatic of a panic attack induced by the imminent death of something.

Of what?

Of memory. It's as though we're suffering the symptoms of a peculiar form of cultural dementia: forgetfulness, atrophied thought, impoverished attention span, confusing people with objects, an increasing inability to tell the difference between what is real from what is not. The loss of certainty about who we are is tied to the illusion that we can be whoever we want. More than ever, it seems we are struggling with the addiction of image dependence.

But all this cannot be laid solely at the door of digital technology, surely?

No it can't. Problems remembering who and where we are, began to surface much earlier, but the digital age has sharply accelerated our indifference to them and enhanced an identity crisis.

We have sailed away somewhat, from the source of our discussion, although not from one of its implications. But let's row back to the ships' crews: you were describing what it is you see in them.

When I look, I'm gazing into something rare which no longer exists: the amateur innocence of a pre-digital camera clicked by an amateur eye. In these photos, there's an enthralling mysteriousness that holds and absorbs the attention. I think of the fate of these photos, and of the sailors in them. I try to imagine the seconds that led to the blink of the shutter. Then, after that, the astonishing wait, sometimes for months, before the film could be developed and the pictures held. This delay - between taking a picture and seeing the result - changed what is shown and how sailors narrated their world. The chemical darkness of the developing process slowed down and therefore reinforced the substance of appearances the digital image has lost. The prints were handed round, the source of shared laughter; or circumstances prevailed so that they were printed only after a voyage, when everyone in the pictures had dispersed. Then, they became reminiscent keepsakes stuck in albums, or were tucked away un-regarded in the backs of drawers. When finally they surface again, they're stained and faded, dotted with spots, corners thumbed, remembered names scrawled on the back in blurred ballpoint, and for those who slipped the mind, a question mark. These signs of neglectful, precious use are real and beautiful. And so are the awkward compositions, the unskilled exposures, blurry camera shake, out-of-focus figures - a wonderful regime of artlessness which, paradoxically, in time attains the status of art, all the more so because such loftiness was never in the picture.

What about the figures in these images?

From a distance, whatever they reveal, the repertoire is as narrow and confined as a steamship. But when I look closer, horizons open up as though I'm being taken into their private confidence. The silent eloquence of these waterlogged watch-keepers astonishes me: the dated spectacles, homespun haircuts, uniform jackets; accumulated emblems soundless as shadows; the hull rusting in the salt air. I see not as they saw: the luminous rays falling across deserted 
decks, equatorial skies, unbroken waves, the first signs of landfall. Rather, I witness brooding associations running everywhere beyond my grasp, and find myself enquiring of these seafarers: "Do you still live?"

\section{EPILOGUE}

Certain experiences mark us deeply. They stand out from the background and can come to define the shape of our lives. What haunts us persists in memory. What is puzzling of course is why, of all those things we might have remembered across all the incidents and accidents of a life, some memories retain a resonance which seems out of all proportion to the original experience at their source; others, we thought would be remembered, vanish without trace.

The involuntary nature of personal memory sometimes challenges the stories we want to tell ourselves about our past. And, in so far as coherence comes from recognising patterns, it's valuable for us to speculate not only why some images never leave us, but also how in other ways a few memories can seem to stand for the whole of our experience.

Our lives are littered with unfinished business. And whereas endings are always inconclusive, beginnings often are disclosed by coincidences that are in themselves no more than a moment's hesitation: a sight, a smell, a tune, a colour - a chance event that collapses time and transcends space.

I used to think it was possible to will a form of seeing which Schopenhauer implies is egoless and where, in a state of relaxed or wearied attentiveness, we become absorbed in the world of appearances, seized by the intensity of seeing into things. But then I realised that those kinds of disruptions of habitual consciousness are rare and cannot be willed or anticipated. Theirs is one of surprise that catches the ego off guard and in a curious paradox, brings us down to earth, and yet also takes us somewhere else.

It is not always clear why we need to go back to recover something yet the need itself is as telling as it is ancient, for Homeric narratives long prefigured psychoanalysis, where a god's-eye view of time gives a glimpse into why it might be necessary to go back for something we can't forget. So it is for me, a former seafarer, that sailors' photographs and the images of ships retrieve an intangible loss.

They fail of course. But this dilemma makes sense of photographs as a radical way to recover memory imaginatively from the past and impossibly attempt to arrest the destiny of clocks.

What survives can only ever be as fugitive as illusions are but the need to make images is haunted by the poetic power of seeing the pellucid appearances of 'things'. Not all appearances, not all things, but for each of us, a private handful of sparks. These appearances are not those we see outside ourselves but rather what happens when they are made immanent by perception and then worked upon by memory and the imagination. This is what makes them inviolably ours.

We take the world into us as appearances. There, it becomes invisible. Yet this invisibility illuminates almost all sense we can make of experience. It is only when we return these appearances back out into the world's gaze (and our own) as objects, actions, gifts and so forth, that we get faint insights into the immanence of what it means to be here for now, learning to see things from the inside out. 
Copyright (C) 2016 Robert Clarke

Photo credits: copyright of the author 